\title{
Microstructure and Mechanical Properties of as-Cast Mg-Li-Al-xSi Alloys
}

\author{
Zhang Zhenyu ${ }^{1}, \quad$ Peng Xiaodong ${ }^{1,2}, \quad$ Yan Lei $^{1}, \quad$ Yang Yan ${ }^{1}, \quad$ Li Yangmin ${ }^{1}, \quad$ Ma Yi ${ }^{1}$, \\ Li Mengluan'
}

${ }^{1}$ Chongqing University, Chongqing 400045, China; ${ }^{2}$ National Engineering Research Center for Magnesium Alloys, Chongqing 400044, China

\begin{abstract}
As-cast Mg-9Li-3Al- $x \mathrm{Si}(x=0,0.1,0.5,1.0, \mathrm{wt} \%)$ alloys were prepared and then investigated by optical microscope (OM), scanning electron microscope (SEM) and X-ray diffractometer (XRD) and mechanical properties test. Results show that the as-cast $\mathrm{Mg}-9 \mathrm{Li}-3 \mathrm{Al}$ alloy consists of $\alpha-\mathrm{Mg}, \beta$ - $\mathrm{Li}$ and $\mathrm{Mg}_{17} \mathrm{Al}_{12}$ phases. The addition of $\mathrm{Si}$ leads to the formation of new phase $\left(\mathrm{Mg}_{2} \mathrm{Si}\right)$ and the refinement of the grain size. Moreover, $\mathrm{Si}$ addition can restrain the formation of $\mathrm{Mg}_{17} \mathrm{Al}_{12}$. However, when the content of $\mathrm{Si}$ is excessive, $\alpha-\mathrm{Mg}$ phase will be coarsened and Chinese script $\mathrm{Mg}_{2} \mathrm{Si}$ phase is formed in the phase boundary. The tensile strength of alloys initially increases and then decreases while the elongation decreases monotonically with the increase of Si content. Specifically, as-cast Mg-9Li-3Al-0.1 $\mathrm{Si}$ shows a favorable combination of ductility and strength with an ultimate tensile strength of 182.5 MPa, yield strength of $136.8 \mathrm{MPa}$, and an elongation of $12.1 \%$.
\end{abstract}

Key words: magnesium alloy; microstructure; mechanical properties; silicon

The demand for lightweight structural materials is fueled by the strategic requirement of reducing the greenhouse gas emissions and energy consumption ${ }^{[1,2]}$. $\mathrm{Mg}$ alloys, with merits of low density, excellent physical and mechanical properties, have been paid much attentions to in recent years ${ }^{[3]}$. However, due to their hcp crystalline structure and high axial ratio ( $c / a) 1.6236$, the deformation capacity of $\mathrm{Mg}$ alloys is relatively poor. For example, the elongation of commonly used as-cast AZ31 and AM60 are 4.8\% and 3.0\%, respectively, which consequently hinders the application of $\mathrm{Mg}$ alloys in many fields. $\mathrm{Li}$ additions to $\mathrm{Mg}$ have been reported to not only reduce the density, but also improve the ductility. $\mathrm{Li}$ additions decreases $c / a$ axial ratio, even changes the crystalline structure of $\mathrm{Mg}$ alloys ${ }^{[4]}$, which is beneficial to the improvement of ductility. Hence, Mg-Li alloys shows wide application prospects in the aircraft, airspace and military industry ${ }^{[4-8]}$. However, the strength of $\mathrm{Mg}-\mathrm{Li}$ alloys is low. For example, the tensile strength of LA141 (Mg-14Li-1 Al) alloy is only $138 \mathrm{MPa}$. Thus the ex- tensive application of $\mathrm{Mg}-\mathrm{Li}$ alloys is restricted.

According to $\mathrm{Mg}-\mathrm{Li}$ binary phase diagram, $\alpha-\mathrm{Mg}$ with hcp lattice and $\beta$-Li with bcc lattice coexist in $\mathrm{Mg}$-Li alloys when the content of $\mathrm{Li}$ is between $5.7 \mathrm{wt} \% \sim 10.3 \mathrm{wt} \% . \alpha-\mathrm{Mg}$ phase of $\mathrm{Mg}$ alloys is beneficial to the strength while $\beta$ - $\mathrm{Li}$ phase is good to the ductility. Therefore, dual-phase Mg-Li alloys attract more and more attention. Thus, dual-phase $\mathrm{Mg}-\mathrm{Li}$ alloy is focused in this research.

Improving the mechanical properties of $\mathrm{Mg}-\mathrm{Li}$ alloys via alloying elements such as $\mathrm{Al}, \mathrm{Mn}, \mathrm{Sr}$ and $\mathrm{Y}$ is an effective way being studied ${ }^{[9,10]}$. With the addition of $\mathrm{Al}$, the mechanical properties of $\mathrm{Mg}$-Li alloy can be significantly improved due to its high solid solubility and density in $\mathrm{Mg}$. However, the strength of $\mathrm{Mg}$-Li-Al alloy remains limited. Therefore, it is necessary to introduce some other elements. Si with relatively low price and low density $\left(2.33 \mathrm{~g} / \mathrm{cm}^{3}\right)$ has been used to improve the mechanical properties of $\mathrm{Mg}$-Li-Al alloys. Si mainly exists in the form of $\mathrm{Mg}_{2} \mathrm{Si}$ intermetallic compound because its solubility in $\mathrm{Mg}$ is only

Received date: August 13, 2016

Foundation item: Fundamental Research Funds for the Central Universities of China (106112015CDJXY130011, CDJZR14130007)

Corresponding author: Peng Xiaodong, Ph. D., Professor, College of Materials Science and Engineering, Chongqing University, Chongqing 400044, P. R. China, Tel: 0086-23-65106774, E-mail: pxd@cqu.edu.cn 
$0.003 \%$, according to the phase diagram of $\mathrm{Mg}-\mathrm{Si} . \mathrm{Mg}_{2} \mathrm{Si}$ possesses high melting point $\left(1085^{\circ} \mathrm{C}\right)$, high hardness $\mathrm{HV}$ (4600 MPa), high elasticity modulus $(120 \mathrm{GPa})$, low density and low thermal expansivity $\left(7.5 \times 10^{-6} \mathrm{~K}^{-1}\right)^{[11,12]}$. Therefore, adding $\mathrm{Si}$ is an effective way to improve the microstructure and mechanical properties of $\mathrm{Mg}-\mathrm{Li}$ alloy ${ }^{[13-17]}$. However, if $\mathrm{Mg}_{2} \mathrm{Si}$ appeared with blocky structure or in Chinese character shape, it will greatly worsen the mechanical properties of alloy ${ }^{[12,16]}$. Therefore, the key aim of current researches is to control the size, shape and distribution of $\mathrm{Mg}_{2} \mathrm{Si}$ in alloy. Currently, there are few reports about how to obtain small and dispersed $\mathrm{Mg}_{2} \mathrm{Si}$. This paper explored an economical way to improve the comprehensive mechanical property of $\mathrm{Mg}$-Li alloy by adding a small amount of $\mathrm{Si}$, which will broaden the application area of $\mathrm{Mg}-\mathrm{Li}$ alloy.

\section{Experiment}

The starting materials used in this study are pure $\mathrm{Mg}$ (99.99\%), pure Li (99.99\%), pure Al (99.99\%) and Mg-10Si master alloy. Target alloys were melted in a melting furnace under the protection of argon atmosphere. Firstly, the materials were put into graphite crucibles. Then they were heated to $720{ }^{\circ} \mathrm{C}$. Subsequently, raising the temperature to $780^{\circ} \mathrm{C}, \mathrm{Al}$ and $\mathrm{Mg}$-10Si were added into liquid magnesium and maintained for $20 \mathrm{~min}$. Then Li was added at the temperature $720{ }^{\circ} \mathrm{C}$ for $10 \mathrm{~min}$. Finally, the liquid alloy was poured into metal molds $(\Phi 90 \mathrm{~mm} \times 50 \mathrm{~mm})$ to form the as-cast alloy ingots.

The specimens were cut from the center of the as-cast ingots. The samples were prepared using standard mechanical grinding and polishing procedures followed by etching using $2 \%$ nital. Then microstructure was observed by optical microscope (Olympus), scanning electron microscope (SEM, JOEL/JSM-6460LV) with X-ray energy dispersive spectrometer (EDS, Oxford) and X-ray diffractometer (XRD, D/MAX-A). In addition, tensile tests of the alloys were conducted at ambient temperature on an SANS CMT-5105 material testing machine with the speed of 2.0 $\mathrm{mm} / \mathrm{min}$.

\section{Results and Discussion}

\subsection{Microstructure of alloys}

Fig. 1 shows the microstructure of as-cast $\mathrm{Mg}-9 \mathrm{Li}-3 \mathrm{Al}-$ $x \mathrm{Si}$ alloy. In the figure, the alloys consist of $\alpha-\mathrm{Mg}$ phase and $\beta$-Li phase. The white area is $\alpha-\mathrm{Mg}$ phase while the black is $\beta$-Li phase area. The white $\alpha-\mathrm{Mg}$ of alloy in Mg-9Li-3Al alloy shows as a thick block with black particles inside as shown in Fig.1a.

With the increase of Si content, the grain size of $\alpha-\mathrm{Mg}$ increases first and then decreases. When the content of $\mathrm{Si}$ is $0.1 \%$ (Fig.1b) and $0.5 \%$ (Fig.1c), the refinement of $\alpha$-Mg is obvious and the distribution of $\alpha-\mathrm{Mg}$ phase becomes more homogeneous. When Si content increases to $1.0 \%$ (Fig.1d), the grain size of $\alpha$-Mg becomes larger. Besides, some black particles and new Chinese script phase are formed at phase boundaries.

The SEM images of as-cast Mg-9Li-3Al- $x \mathrm{Si}$ alloys are shown in Fig.2. The morphology of SEM is basically consistent with the result of optical microscope. The black lump one is $\alpha-\mathrm{Mg}$ and the lighter area is $\beta$-Li. Some tiny white particle phases exist at the phase boundary of $\alpha / \beta$. With the increase of $\mathrm{Si}$, the grain of alloys are refined first and then coarsened while white particle phase gradually increases on the edge of $\alpha$ phase. When the content of Si is $0.5 \%$ (Fig.2c), a blocky white particle phase appears in alloy. When the content of Si increases to $1 \%$ (Fig.2d), the blocky white particle phase gets more and bigger. The preliminary speculation is that the formation of the white particles is related to Si. Hence, adding a certain amount of Si can refine the microstructure of alloys, but excessive amount will coarsen it.

Fig. 3 shows the XRD patterns of as-cast Mg-9Li-3Al- $x \mathrm{Si}$ alloy. The XRD indicates that $\mathrm{Mg}-9 \mathrm{Li}-3 \mathrm{Al}$ alloy mainly consists of $\alpha-\mathrm{Mg}, \beta$ - $\mathrm{Li}$ and $\mathrm{Mg}_{17} \mathrm{Al}_{12}$ phases. With the increase of $\mathrm{Si}$ content, new $\mathrm{Mg}_{2} \mathrm{Si}$ phase appears with the gradual disappearance of $\mathrm{Mg}_{17} \mathrm{Al}_{12}$, which illustrates that $\mathrm{Si}$ restrains the formation of $\mathrm{Mg}_{17} \mathrm{Al}_{12}$. In Fig.3, the diffracted intensity of $\alpha-\mathrm{Mg}$ declines while the diffraction peak intensities of $\beta$ - $\mathrm{Li}$ and $\mathrm{Mg}_{2} \mathrm{Si}$ gradually increases, which shows that the addition of $\mathrm{Si}$ decreases $\alpha-\mathrm{Mg}$ slowly and increases
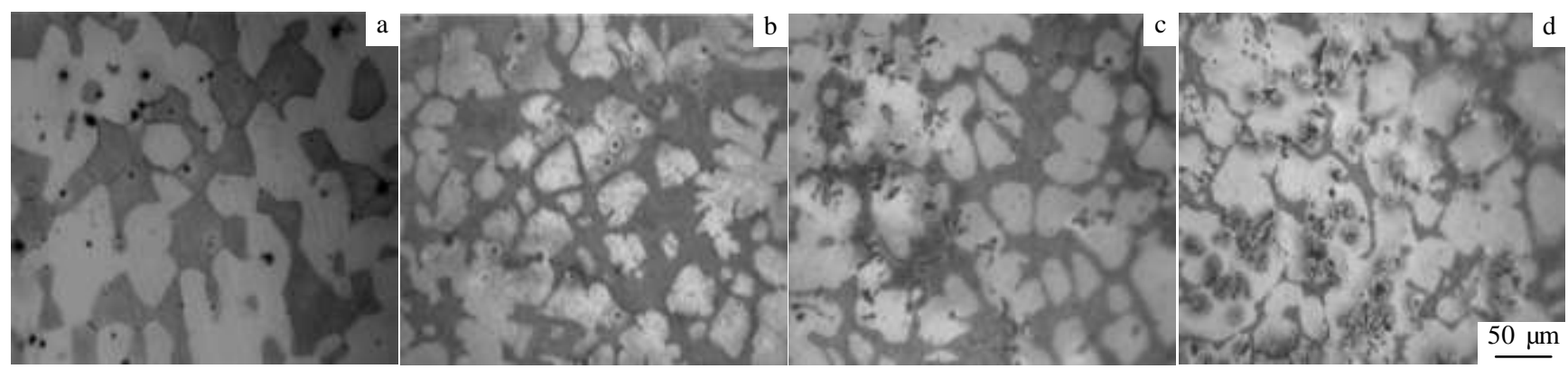

Fig.1 Microstructures of as-cast Mg-9Li-3Al- $x \mathrm{Si}$ alloys: (a) $x=0$, (b) $x=0.1$, (c) $x=0.5$, and (d) $x=1.0$ 

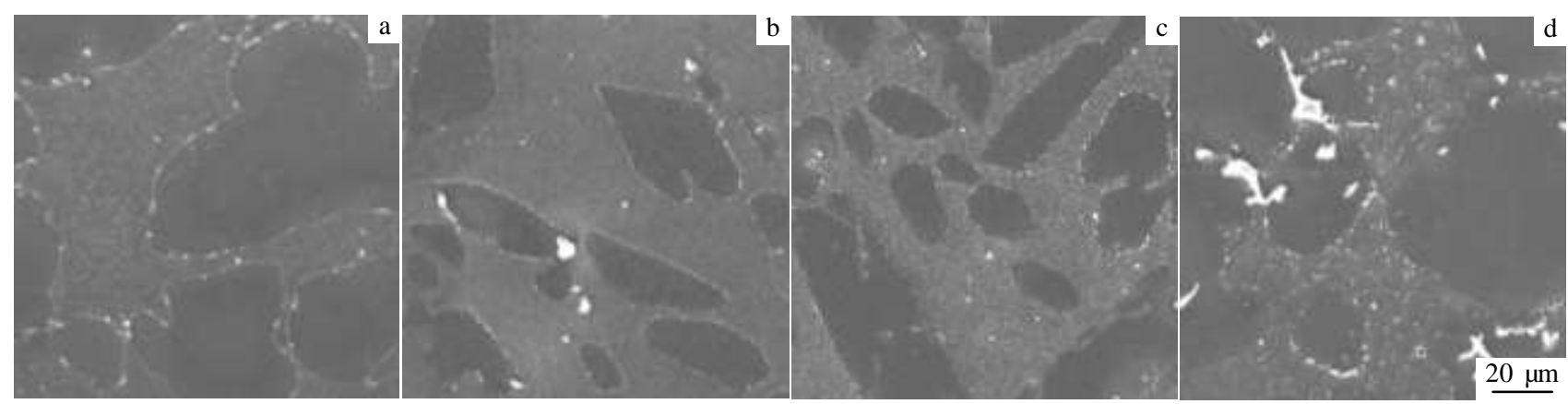

Fig.2 SEM images of as-cast Mg-9Li-3Al- $x$ Si alloys: (a) $x=0$, (b) $x=0.1$, (c) $x=0.5$, and (d) $x=1.0$

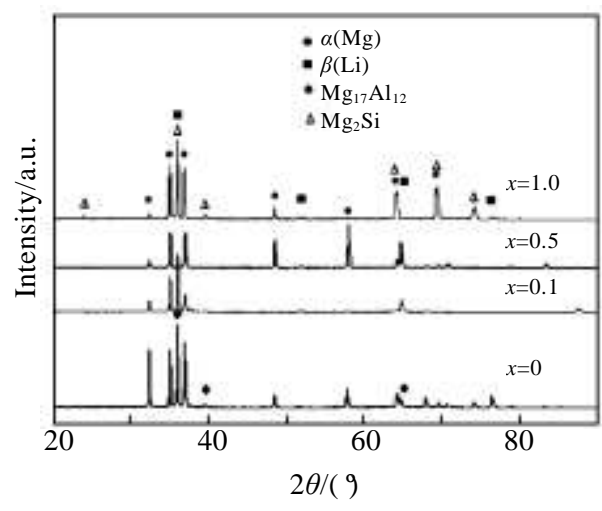

Fig.3 XRD results of as-cast $\mathrm{Mg}-9 \mathrm{Li}-3 \mathrm{Al}-x \mathrm{Si}$ alloy

$\mathrm{Mg}_{2} \mathrm{Si}$ gradually. The result accords with the previous analysis of alloy SEM morphology.

Further analysis is required to determine the white particle phase of Mg-9Li-3Al- $x \mathrm{Si}$ alloy. Fig.4 and Fig.5 show EDS analysis of as-cast $\mathrm{Mg}-9 \mathrm{Li}-3 \mathrm{Al}$ and $\mathrm{Mg}-9 \mathrm{Li}-3 \mathrm{Al}-0.5 \mathrm{Si}$ alloys, respectively. The EDS point analysis, conducted at specific locations labeled as A and B, shows the presence of $\mathrm{Mg}$ and $\mathrm{Al}$ element in this region. Spectrogram $\mathrm{C}$ and $\mathrm{D}$ mark the blocky white particles on the edge of $\alpha-\mathrm{Mg}$. As shown in Fig.5, the main elements in white particle phase are $\mathrm{Mg}, \mathrm{Al}$ and $\mathrm{Si}$ and the mole ratio of $\mathrm{Mg}$ to $\mathrm{Si}$ at location $\mathrm{C}$ and D is approximately $2: 1$. Combined the EDS results (Fig.5) with the XRD results, it can be confirmed that the intermetallic compounds are mainly $\mathrm{Mg}_{2} \mathrm{Si}$.

As shown in Fig. 1 and Fig.2, the $\alpha-\mathrm{Mg}$ phase gets smaller first and then bigger, while the proportion of $\alpha-\mathrm{Mg}$ phase keeps reducing with increasing $\mathrm{Si}$ content. This phenomenon can be explained by the refinement mechanism of Si. Firstly, Si with high melting point and low solubility in $\mathrm{Mg}$, gathered in the forefront of the solid-liquid interface, which led to the formation of constitutional supercooling during the solidification of alloys. Consequently, the activated core of constitutional supercooling zone raised the nucleation rate in the interface, which is beneficial to grains refinement. Secondly, with the addition of $\mathrm{Si}, \mathrm{Mg}_{2} \mathrm{Si}$ with high
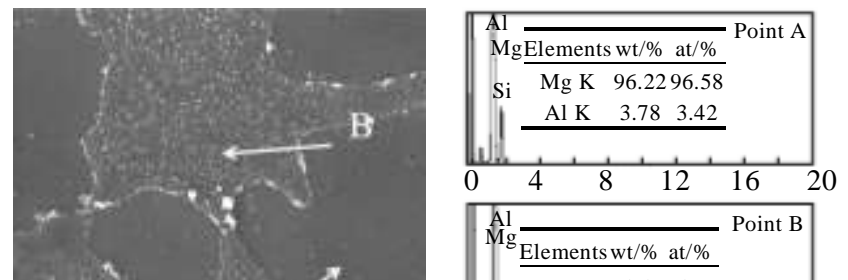

Fig.4 SEM morphology and EDS results of as-cast Mg-9Li-3Al alloy
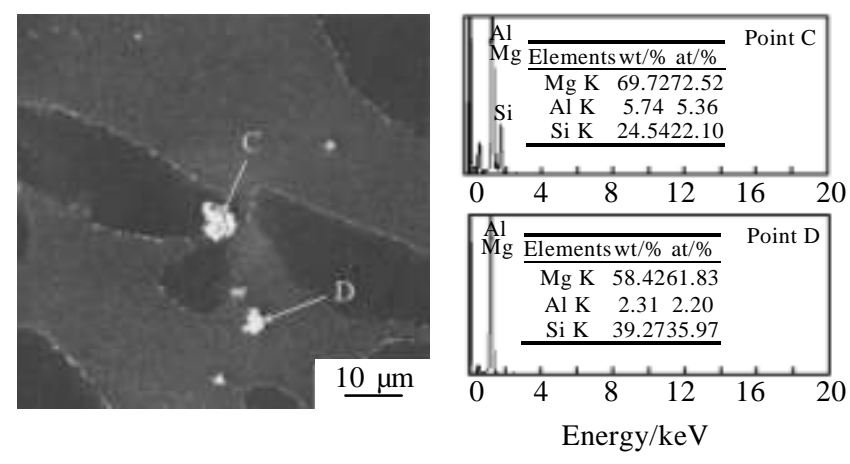

Fig.5 SEM morphology and EDS results of as-cast Mg-9Li3Al-0.5Si alloy

melting point was formed at the phase boundary of $\alpha-\mathrm{Mg}$, hindering the growth of $\alpha-\mathrm{Mg}$ grain. Therefore, when the content of $\mathrm{Si}$ is $0.1 \%$ or $0.5 \%$, the $\alpha-\mathrm{Mg}$ phases are obviously refined. But when the content of $\mathrm{Si}$ is $1.0 \%, \mathrm{Mg}_{2} \mathrm{Si}$ phase gets bigger, changing from dispersed particles to bulk or Chinese script shape which cannot effectively hinder the growth of $\alpha-\mathrm{Mg}$ and dislocation moving.

\subsection{Mechanical properties of Mg-9Li-3Al- $x$ RE alloys}

The mechanical properties of as-cast $\mathrm{Mg}-9 \mathrm{Li}-3 \mathrm{Al}-x \mathrm{Si}$ alloys at room temperature are listed in Table 1. Fig.6 shows the influence of Si content on the mechanical properties of as-cast alloys.

Table 1 Mechanical properties of as-cast Mg-9Li-3Al-xSi alloys 


\begin{tabular}{cccc}
\hline$x$ & $\sigma_{0.2} / \mathrm{MPa}$ & $\sigma_{\mathrm{b}} / \mathrm{MPa}$ & $\delta_{5} / \%$ \\
\hline 0 & 89.6 & 114.3 & 14.5 \\
0.1 & 136.8 & 182.5 & 12.1 \\
0.5 & 132.6 & 168.2 & 7.6 \\
1.0 & 123.8 & 159.7 & 5.3 \\
\hline
\end{tabular}

As shown in Table 1 and Fig.6, the addition of Si can improve the strength significantly with a little decrease of elongation. Both the yield strength and the tensile strength of alloys increase first and then decrease with the increase of $\mathrm{Si}$ content. Mg-9Li-3Al alloy with $0.1 \% \mathrm{Si}$ addition has maximum tensile strength of $182.5 \mathrm{MPa}$ and yield strength of $136.8 \mathrm{MPa}$, with elongation of $12.1 \%$ (remaining relatively high), which is $59.6 \%$ and $52.6 \%$, higher than Mg-9Li-3Al alloy, respectively. However, the further increase of $\mathrm{Si}$ content results in the reduction of tensile strength. Thus appropriate Si content can significantly improve the comprehensive mechanical properties of as-cast Mg-9Li-3Al alloy.

$\mathrm{Mg}_{17} \mathrm{Al}_{12}$ in Mg-9Li-3Al alloy is a kind of brittle phase, which is mainly distributed in the interface of $\alpha$ phase and $\beta$ phase. It can cut apart the interface of $\alpha$ phase and $\beta$ phase. That is why the strength of $\mathrm{Mg}-9 \mathrm{Li}-3 \mathrm{Al}$ alloy is relatively low ${ }^{[18]}$. With increasing of Si content, $\mathrm{Mg}_{17} \mathrm{Al}_{12}$ phase will be replaced by $\mathrm{Mg}_{2} \mathrm{Si}$ phase gradually. Then $\alpha-\mathrm{Mg}$, as a strengthening phase, becomes finer and more homogeneous so that strength initially increases. In addition, $\mathrm{Mg}_{2} \mathrm{Si}$, as one of high temperature hard phases, distributes in the interface of $\alpha$ phase and $\beta$ phase as particles or small strips. It can effectively hinder the movements of dislocations, which is beneficial to the improvement of mechanical properties. Therefore, the comprehensive mechanical property of Mg-9Li-3Al-0.1Si alloy is the best.

However with further increase of Si content, the strength of alloys decreases. The reason is that when the content of $\mathrm{Si}$ is excessive, the intermetallic compound $\mathrm{Mg}_{2} \mathrm{Si}$ with blocky structure or in Chinese script shape can't effectively refine the grain and hinder dislocation movement, causing the decrease of alloy strength.
The elongation of as-cast $\mathrm{Mg}-9 \mathrm{Li}-3 \mathrm{Al}-x \mathrm{Si}$ alloys keeps decreasing with the increase of $\mathrm{Si}$ content. It is because $\mathrm{Mg}_{2} \mathrm{Si}$ intermetallic compound is mainly distributed in the interface of $\alpha$ phase and $\beta$ phase, impeding the dislocation moving by its pinning effect. Hence the plasticity of alloy is reduced. With the further increase of $\mathrm{Si}$ content, $\mathrm{Mg}_{2} \mathrm{Si}$ is formed with the blocky structure or Chinese script shape. The bulky $\mathrm{Mg}_{2} \mathrm{Si}$ is apt to create a stress concentration, generating the cracks which are liable to spread along the boundary of $\mathrm{Mg}_{2} \mathrm{Si}$ and $\alpha-\mathrm{Mg}$. The growth of $\mathrm{Mg}_{2} \mathrm{Si}$ promotes the generating and spreading of the cracks, leading to the degradation of comprehensive mechanical property of alloys ${ }^{[19]}$.

As shown in Fig.7, the fracture mechanism of as-cast Mg-9Li-3Al- $x$ Si alloys is the typical composite rupture, in which some tearing ridges of dimple and cleavage rupture exist. In Fig.7a, the fracture of as-cast Mg-9Li-3 Al alloy has many dimples which are large and deep with few tearing ridges. With the addition of $\mathrm{Si}$, especially when the content of $\mathrm{Si}$ is $1 \%$, the dimples become fewer and the diameter gets smaller while the number of tearing ridges increases. That makes the fracture of alloy possess the features of composite rupture of dimple rupture and cleavage rupture. The fracture appearance of as-cast $\mathrm{Mg}-9 \mathrm{Li}-3 \mathrm{Al}-x \mathrm{Si}$ alloy is consistent with its mechanical property of mentioned above. These features precisely explain why the plasticity of alloy decreases.

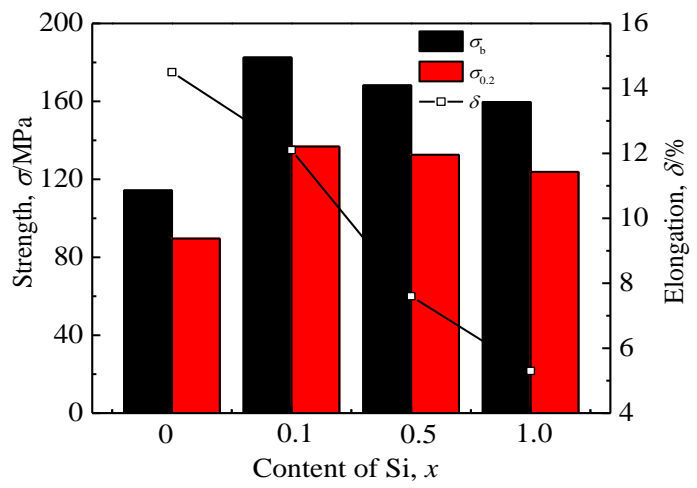

Fig.6 Mechanical properties of Mg-9Li-3Al- $x \mathrm{Si}$ alloys

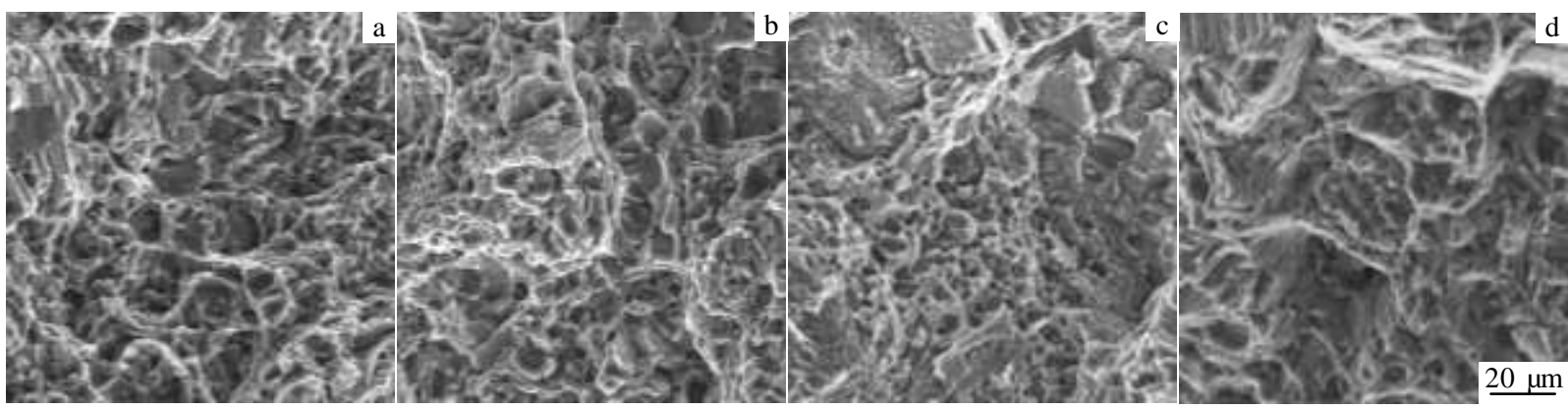

Fig.7 Fracture morphology of as-cast Mg-9Li-3Al- $x$ Si alloys: (a) $x=0$, (b) $x=0.1$, (c) $x=0.5$, and (d) $x=1.0$ 
$\mathrm{Mg}_{2} \mathrm{Si}$ at the phase boundary. However, when the content of $\mathrm{Si}$ is excessive, the $\alpha-\mathrm{Mg}$ gets bulky and blocky structure or Chinese script $\mathrm{Mg}_{2} \mathrm{Si}$ is formed in the phase boundary.

2) $\mathrm{Mg}-9 \mathrm{Li}-3 \mathrm{Al}$ mainly consists of $\alpha-\mathrm{Mg}, \beta$ - $\mathrm{Li}$ and $\mathrm{Mg}_{17} \mathrm{Al}_{12}$ phases. With the addition of $\mathrm{Si}$, the main phases are $\alpha-\mathrm{Mg}, \beta-\mathrm{Li}$ and $\mathrm{Mg}_{2} \mathrm{Si}$ phases. Moreover, the addition of Si can restrain the formation of $\mathrm{Mg}_{17} \mathrm{Al}_{12}$.

3) With the increase of $\mathrm{Si}$ content, the strength of Mg-9Li-3Al- $x$ Si alloys increases first and then decreases, while the elongation decreases. When the content of $\mathrm{Si}$ is $0.1 \%$, the alloy shows a favorable combination of ductility and strength with an ultimate tensile strength of $182.5 \mathrm{MPa}$, yield strength of $136.8 \mathrm{MPa}$, and an elongation of $12.1 \%$. Compared with $\mathrm{Mg}-9 \mathrm{Li}-3 \mathrm{Al}$ alloy, the yield strength and tensile strength increase by $59.6 \%$ and $52.6 \%$, respectively.

4) The fracture of alloy consists of tearing ridges and some dimples, which is the typical composite rupture of dimple rupture and cleavage rupture. With the increase of $\mathrm{Si}$ content, the dimples become fewer and smaller while the number of tearing ridges increases gradually.

\section{References}

1 Wang J, Liu R D, Luo T J et al. Materials \& Design[J], 2013, 47: 746

2 Yang Y, Peng X D, Wen H M et al. Metallurgical and Materials Transactions $A[\mathrm{~J}], 2013,44: 1101$

3 Xiang Q, Wu R Z, Zhang M L. Journal of Alloys and Compounds[J], 2009, 477: 832

4 Xu T C, Peng X D, Jiang J W et al. Transaction of Nonferrous Metals Society of China[J], 2014, 24: 2752
5 Peng Xiaodong, Li Junchen, Li Wenjuan. Rare Metal Materials and Engineering [J], 2013, 42(10): 1993

6 Vinod Kumar, Govind, Rajiv Shekhar et al. Materials Science and EngineeringA[J], 2012, 547: 38

7 Wu Ruizhi, Qu Zhikun, Zhang Milin. Materials Science and Engineering A [J], 2009, $516: 96$

8 Song P W. Special Casting \& Nonferrous Alloys[J], 2011, 31(4): 311 (in Chinese)

9 Golmakaniyoon S, Mahmudi R. Materials Science and Engineering $A[\mathrm{~J}], 2011,528: 1668$

10 Luo A A. International Materials Reviews[J], 2004, 49: 13

11 Jiang Q C, Wang H Y, Wang Y et al. Materials Science and Engineering A [J], 2005, $392: 130$

12 Mabuchi M, Higashi K. Acta Materialia[J], 1996, 44: 4611

13 Chen K, Li Z Q, Liu J S et al. Journal of Alloys and Compounds[J], 2009, 487: 293.

14 Zhang M X, Kelly P M, Easton M A et al. Acta Materialia[J], 2005, 53: 1427

15 Zhang M X, Kelly P M, Qian M et al. Acta Materialia[J], 2005, 53: 3261

16 Lu Y Z, Wang Q D, Zeng X Q et al. Materials Science and Engineering $A[\mathrm{~J}], 2001,301: 257$

17 Zhang Jinghuai, Niu Xiaodong, Qiu Xin et al. Journal of Alloys and Compounds[J], 2009, 471: 326

18 Zhang C X, Guan S K, Chen H J et al. Materials for Mechanical Engineering [J], 2004, 28(9): 21 (in Chinese)

19 Cong Mengqi, Li Ziquan, Liu Jinsong et al. Journal of Alloys and Compounds[J], 2012, 539: 16

\title{
铸态Mg-Li-Al- $x \mathrm{Si}$ 合金微观组织和力学性能
}

\author{
张振宇 ${ }^{1}$, 彭晓东 ${ }^{1,2}$, 颜 䂞 ${ }^{1}$, 杨 艳 $^{1}$, 李杨敏 ${ }^{1}$, 麻 毅 $^{1}$, 李孟孪 ${ }^{1}$ \\ (1. 重庆大学, 重庆 400045)
}

(2. 国家镁合金材料工程技术研究中心，重庆 400044)

\begin{abstract}
摘 要: 实验铸造了 $\mathrm{Mg}-9 \mathrm{Li}-3 \mathrm{Al}-x \mathrm{Si}(x=0,0.1,0.5,1.0$, 质量分数, \%) 合金并通过 $\mathrm{OM}, \mathrm{SEM}, \mathrm{XRD}$ 和力学性能测试对其进行了研究。 结果表明: 铸态 $\mathrm{Mg}-9 \mathrm{Li}-3 \mathrm{Al}$ 合金组织中主要由 $\alpha-\mathrm{Mg} 、 \beta-\mathrm{Li} 、 \mathrm{Mg}_{17} \mathrm{Al}_{12}$ 相组成。加入 $\mathrm{Si}$ 后, 合金中出现了新相 $\mathrm{Mg}_{2} \mathrm{Si}$, 晶粒得到了明显细化,

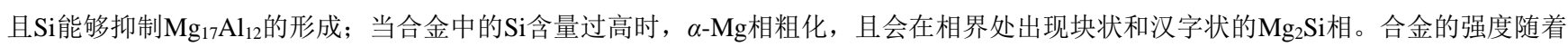
$\mathrm{Si}$ 含量的增加呈现先增加后降低的趋势，合金的延伸率随着 $\mathrm{Si}$ 含量的增加呈现逐渐降低的趋势。当合金中 $\mathrm{Si}$ 含量为 $0.1 \%$ 时，抗拉强度达 到最大值 $182.5 \mathrm{MPa}$, 延伸率为 $12.1 \%$ 。
\end{abstract}

关键词：镁合金; 显微组织; 力学性能; 硅元素

作者简介: 张振宇, 男, 1991 年生, 硕士, 重庆大学材料科学与工程学院, 重庆 400045, 电话: 023-65106774, E-mail: zy791888997@163.com 